\title{
Eating behavior affects cardio-metabolic risk in high school teenagers in a developing country
}

Rita Suhadi†, Phebe Hendra, Dita Maria Virginia, Christianus Heru Setiawan

pISSN: 0853-1773 • elSSN: 2252-8083 https://doi.org/10.13181/mji.oa.193494 Med J Indones. 2020;29:71-81

Received: January 14, 2019 Accepted: August 28, 2019

\section{Authors' affiliations:}

Department of Pharmacology and Clinical Pharmacy, Faculty of Pharmacy, Universitas Sanata Dharma, Yogyakarta, Indonesia

\section{Corresponding author:}

Phebe Hendra

Department of Pharmacology and

Clinical Pharmacy, Faculty of Pharmacy,

Campus 3, Universitas Sanata Dharma,

Jalan Paingan, Maguwoharjo, Yogyakarta

55281, Indonesia

Tel/Fax: +62-274-883037/

+62-274-886529

E-mail: phebe_hendra@usd.ac.id

†Deceased in October 20, 2019

\begin{abstract}
BACKGROUND Modernization negatively changes lifestyle, characterized by excessive eating and reduced energy consumption, and concurrently increases the cardiometabolic risk. This study was aimed to evaluate the association between eating behavior and cardio-metabolic risk factors including body mass index (BMI) in percentile, blood pressure (BP) in percentile, waist circumference, and heart rate in total subjects and gender sub-groups.
\end{abstract}

METHODS This analytical cross-sectional study was done from July to November 2018. High schools in four provinces of Indonesia and students were selected using purposive sampling. Subjects' profiles were collected from interview and cardio-metabolic parameters were measured at the study sites. Data were analyzed with chi-square and independent $t$-test.

RESULTS Subjects who were overweight/obese and had high BP accounted for $27.1 \%$ and $9.3-12.0 \%$ of the total subjects $(n=768)$, respectively. Subjects who having breakfast tended to have lower BMI $(p=0.006)$, and the lower consumption of western meals had lower heart rate $(p=0.02)$. Male subjects had more meal frequency and had less quantity of snacks than female subjects $(p<0.001)$. Male subjects with routine intake of vegetables had low heart rate $(p=0.03)$. Female subjects with routine breakfast had better BMI $(p<0.001)$, and lower diastolic BP $(p=0.004)$ and waist circumference $(p=0.02)$, whereas those who consumed Western meals had higher heart rate $(p=0.046)$ and waist circumference $(p=0.001)$.

CONCLUSIONS Eating behaviors are likely to affect cardio-metabolic risk factors, and the effects vary within gender groups.

KEYWORDS blood pressure, body mass index, cardiovascular, eating behavior, risk, teenagers
Cardiovascular disease (CVD) due to atherosclerosis has the highest mortality rate worldwide. The mortality rate of CVD accounts for $37 \%$ of the total rate in Indonesia. ${ }^{1}$ A previous study on subjects with low socioeconomic status in Yogyakarta showed medium CVD risk, which was likely to increase metabolic disorders. ${ }^{2}$ The atherosclerotic process initiates since childhood and manifests as CVD in adults. ${ }^{3}$

At the early stage of atherosclerosis, obesity increases the arterial stiffness due to endothelial dysfunction and insulin sensitivity, which intensifies with sodium retention and sympathetic effects and increases the cardiac output and blood pressure (BP). In a population study, the overweight and obese children aged between 9-11 years had higher heart rate and systolic blood pressure (SBP) compared with their normal-weight peers. ${ }^{4}$ Furthermore, the obesity significantly increase the risk of events primary hypertension in children. ${ }^{5} \mathrm{BP}$ in children (<19 years) is generally classified based on BP in 
percentile. ${ }^{6}$ Meanwhile, in the 2017 American College of Cardiology/American Heart Association (ACC/AHA) hypertension guideline, children aged 14 years or above can be categorized normal if the BP is $<120 / 80$ mmHg. ${ }^{7}$ Research shows that sex contributes to cardiometabolic risks and affects the epidemiological profile of such risks. ${ }^{7}$ Male and female subjects have different thresholds of waist circumference, ${ }^{8}$ obesity profiles, ${ }^{9}$ and calculators for body mass index (BMI) percentile ${ }^{10}$ and BP percentile. ${ }^{11,12}$

Eating behavior and lifestyle are two significant factors in childhood obesity. ${ }^{13}$ Children worldwide generally consume excess nutrients including high calories, carbohydrates, saturated fat, and sodium, and their eating behavior resembles that of the Western society. ${ }^{14}$ Modernization also brings development in transportation, which causes less physical activity and a significant decline in energy consumption. ${ }^{15}$ Many studies of eating behavior and cardio-metabolic risk factors have been found in adult subjects, but fewer studies have been conducted in teenagers subjects. Moreover, no research has investigated the relationship of eating behavior covering snack consumption to cardio-metabolic risk factors. In developing countries, including Indonesia, economic growth, environmental changes, and social media have significant influence, that is, they negatively affect lifestyle, including eating behavior and physical activity, and potentially raise obesity and CVD risks. ${ }^{9}$ This study explored whether economic growth, particularly variables of energy consumption, affect some cardio-metabolic parameters. The study was conducted among Indonesian teenagers considering that atherosclerosis commences at the early decades of human life. This study was aimed to evaluate the effect of eating behavior on cardio-metabolic risk factors including $\mathrm{BMI}, \mathrm{BP}$, heart rate, and waist circumference among high school students aged between 14-18 years from four cities of Indonesia and to compare the variables within gender groups.

\section{METHODS}

\section{Type and design of the study}

This observational study with a cross-sectional design was done from July to November 2018. Subjects were senior high school students in four provinces of Indonesia, i.e., South Sumatera (Palembang), Bali (Denpasar and Sukowati), West Borneo (Pontianak), and D.I. Yogyakarta (Yogyakarta and Bantul). The high schools were selected through purposive sampling methods. Subjects' profiles were collected from a face-to-face written interview, and cardio-metabolic parameters were measured at the study sites. The four provinces represent the most populated islands of Indonesia, except for Sulawesi. According to the Basic National Health Survey (2013), ${ }^{16}$ Bali ranked $1^{\text {st }}$ (lowest), West Borneo ranked 2nd, D.I. Yogyakarta ranked 6th, and South Sumatera ranked $30^{\text {th }}$ (almost highest) in terms of the number of underweight teenagers aged 14-18 years.

\section{Subject selection}

Subjects were selected among students of grades 10 or 11 through cluster random sampling. All students in the cluster provided by the schools were included as subjects. Students who do not sign informed consent will be excluded. Minimum subjects in a group were calculated with PS program ${ }^{\circledR 17}$ for independent $t$-test analysis for two main variables (BMI percentile and $\mathrm{BP}$ percentile). The study set the following criteria for sample size of a (type I error of 0.05), power (0.80), mean BMI, and BP difference between male and female subjects $(\delta=5 \%$ ), standard deviation between groups ( $\sigma=15 \%$ ), and ratio between groups $(m=1)$. The minimum subjects based on the calculation in each group were 142, BMI and BP percentile had four groups, and the minimum total subjects became 568 .

\section{Variables}

The independent variable included was eating behavior, and the additional variables were living with parents, cigarette consumption, and exercise. The dependent variables were BMI percentile and BP percentile, and the additional variables were waist circumference, heart rate, absolute BP, and BMI.

\section{Procedures}

All instruments had passed the validity and reliability tests. Omron ${ }^{\circledR}$ sphygmomanometer, weight scale, and stature ruler were calibrated by the Metrology Institution to ensure validity. Reliability test was previously conducted by testing the instruments in three subjects with three replicates. Precision was estimated as coefficient of variation (CV), which was obtained from standard deviation divided with mean value; most instruments with $<5$ replicates were valid for imprecision levels at $<5-10 \% \mathrm{CV} .{ }^{18} \mathrm{All}$ the instruments

mji.ui.ac.id 
used in this study met the reliability requirement, except for heart rate that exceeded the standard of CV at 10.5\%.

The questionnaires for subjects' interviews were tested among 20 volunteers for their understanding of the content. The questionnaire consisted of personal information, i.e., age, gender, living with parents/not, eating behavior, cigarette consumption, and exercise. Personal, eating, and lifestyle behavior were collected from a face-to-face written interview, and the cardiometabolic risk factors were measured at the study sites. BMI percentile was obtained from the online Center for Disease Center calculator ${ }^{10}$ and SBP/DBP percentile was calculated using BP calculator. ${ }^{11,12}$ The data in percentile were calculated based on the profiles of age, gender, and height. Waist circumference was generally measured in percentile, but the threshold for categorization was not available; therefore, this study used the absolute waist parameter.

\section{Data analysis}

The eating behaviors encompassed seven categorical parameters, e.g.: frequency of meals ( $\leq 3$ or >3 times per day), daily breakfast (always/frequent and rare/never), vegetable intake daily (always/frequent and rare/never), fruit intake daily (always/frequent and rare/never), Western/high-calorie meal (yes and no), frequency of snacks ( $\leq 3$ and $>3$ times per day), and snack quantity. These categories in each variable were a favorable aspect of cardio-metabolic risk. Snacks were defined as the amount of food/beverage eaten between meals. Snack quantity obtained from a Likert scale questionnaire which was categorized as moderate/little if the quantity ranged from zero to less than the meal quantity; otherwise, it was categorized as large/massive snack quantity. All data obtained were analyzed even though there was some missing data because it was not filled in by respondents completely.

The BMI percentile was stratified into underweight ( $<5$ th percentile), normal weight ( $5-<85$ th percentile), overweight ( $85-<95$ th percentile), and obesity ( $\geq 95$ th percentile). ${ }^{19}$ The SBP/DBP in percentile was stratified into normal BP (<9oth percentile), prehypertension (90-<95th percentile), stage I hypertension (95th percentile-<stage II threshold), and stage II hypertension (99th percentile plus $5 \mathrm{mmHg}$ ). ${ }^{11,12}$ Meanwhile, the SBP/DBP was also classified by normal absolute $\mathrm{BP}<120 /<80 \mathrm{mmHg}$ according to the 2017 ACC/AHA hypertension guideline, ${ }^{7}$ and the heart rate threshold was $<100$ times per min. ${ }^{20}$ The cut-off of waist circumference for male and female were <90 $\mathrm{cm}$ and $<80 \mathrm{~cm}$, respectively. ${ }^{8}$ Cigarette consumption was defined as active smoking. Physically active was the condition of having $\geq 120$ min exercise weekly and calculated based on at least 4 times weekly, with each activity lasting for $\geq 30 \mathrm{~min}$. The ratio data of cardiometabolic risk factors between the groups were analyzed with independent $t$-test, whereas categorical cardio-metabolic risk profiles between groups were analyzed with gamma test. Association of eating behaviors and cardio-metabolic risk profiles were analyzed with adjusted $p$ linear regression.

\section{Ethical issue}

This descriptive, non-invasive study had complied with the ethical issue guidelines. The study protocol was approved by the Ethics Committee of Universitas Kristen Duta Wacana Yogyakarta (No: 679/C.16/ $\mathrm{FK} / 2018$ ). The study was conducted at schools supervised by school teachers. The subjects were described in the study procedure and requested to sign informed consents prior to their participation. All subjects, treated as anonymous, were allowed to leave the study in case of inconvenience.

\section{RESULTS}

There were 768 subjects, which consisted of male $(n=382)$ and female $(n=386)$ senior high school teenagers. The waist circumferences of 96 subjects were missing due to technical problems during measurement; nevertheless, the subjects still conformed to the minimum sample size. Teenagers had more favorable lifestyle and eating behavior, namely, low cigarette consumption (5.7\%), routine breakfast (55.0\%), vegetable intake daily (57.3\%), Western/highcalorie meal (22.7\%), snack frequency $\leq 3$ times (86.4\%), and moderate/little snack quantity (74.6\%). Few subjects had $\geq 120$ min weekly exercise, particularly in the female group. Moreover, the fruit intake was low and particularly lower in the male group (Table 1).

Subject profile comprising seven eating behavior variables and three other variables (Table 1). All the variables were compared between the gender groups. The numbers of male teenagers who were smokers $(p<0.001)$, performed exercise $\geq 120 \mathrm{~min}$ in a week ( $p<0.001)$, had $>3$ times meal $(p=0.002)$, and consumed snacks in moderate quantity $(p=0.001)$ were higher than female teenagers. The high consumption of 
cigarette and high frequency of meal were variables to elevate cardio-metabolic risk, whereas exercise and moderate quantity of snack were considered as variables to lower cardio-metabolic risk. The remaining eating behavior namely living with parents, have a breakfast, vegetable and fruit intake, Western/highcalorie meal, and snack frequency were not different between the gender groups (Table 1).

Table 1. Characteristic profiles among all subjects and gender sub-groups

\begin{tabular}{|c|c|c|c|c|}
\hline \multirow{2}{*}{ Profiles } & \multirow{2}{*}{$\mathrm{n}(\%)$} & \multicolumn{2}{|c|}{ Gender } & \multirow{2}{*}{$p^{*}$} \\
\hline & & Male, n (\%) (N = 382) & Female, $\mathrm{n}(\%)(\mathrm{N}=386)$ & \\
\hline \multicolumn{5}{|l|}{ Live with parents } \\
\hline Yes & $634(82.5)$ & $308(80.6)$ & $326(84.4)$ & 0.13 \\
\hline No & $129(16.8)$ & $72(18.9)$ & $57(14.8)$ & \\
\hline Missing data ${ }^{\dagger}$ & $5(0.6)$ & $2(0.5)$ & $3(0.8)$ & \\
\hline Cigarette consumption & $44(5.7)$ & $44(11.5)$ & $0(0.0)$ & $<0.001$ \\
\hline \multicolumn{5}{|l|}{ Exercise $\geq 120 \mathrm{~min} /$ week } \\
\hline Yes & $242(31.5)$ & $173(45.2)$ & 69 (17.9) & $<0.001$ \\
\hline No & $525(68.4)$ & $208(54.5)$ & $317(82.1)$ & \\
\hline Missing data ${ }^{\dagger}$ & $1(0.1)$ & $1(0.3)$ & 0 & \\
\hline \multicolumn{5}{|l|}{ Meal frequency } \\
\hline$\leq 3$ times & 721 (93.9) & 349 (91.4) & $372(96.4)$ & 0.002 \\
\hline$>3$ times & $44(5.7)$ & $32(8.3)$ & $12(3.1)$ & \\
\hline Missing data ${ }^{+}$ & $3(0.4)$ & $1(0.3)$ & $2(0.5)$ & \\
\hline \multicolumn{5}{|l|}{ Breakfast } \\
\hline Always/frequent & $421(54.8)$ & $218(57.1)$ & $203(52.6)$ & 0.21 \\
\hline Seldom/never & 345 (44.9) & $163(42.6)$ & $182(47.2)$ & \\
\hline Missing data ${ }^{+}$ & $2(0.3)$ & $1(0.3)$ & $1(0.2)$ & \\
\hline \multicolumn{5}{|l|}{ Vegetable intake } \\
\hline Always/frequent & $438(57.0)$ & $231(60.5)$ & $207(53.6)$ & 0.07 \\
\hline Seldom/never & $326(42.4)$ & $150(39.2)$ & $176(45.6)$ & \\
\hline Missing data ${ }^{\dagger}$ & $4(0.6)$ & $1(0.3)$ & $3(0.8)$ & \\
\hline \multicolumn{5}{|l|}{ Fruit intake } \\
\hline Always/frequent & 314 (40.9) & $147(38.5)$ & $167(43.3)$ & 0.16 \\
\hline Seldom/never & $448(58.3)$ & $233(61.0)$ & $215(55.7)$ & \\
\hline Missing data ${ }^{+}$ & $6(0.8)$ & $2(0.5)$ & $4(1.0)$ & \\
\hline \multicolumn{5}{|c|}{ Western/high-calorie meal } \\
\hline Yes & $174(22.7)$ & $96(25.1)$ & $78(20.2)$ & 0.10 \\
\hline No & $593(77.3)$ & $285(74.6)$ & $308(79.8)$ & \\
\hline Missing data ${ }^{+}$ & $1(0.1)$ & $1(0.3)$ & 0 & \\
\hline \multicolumn{5}{|l|}{ Snack frequency } \\
\hline$\leq 3$ times & $658(85.7)$ & $330(86.4)$ & $328(85.0)$ & 0.57 \\
\hline$>3$ times & $104(13.5)$ & $49(12.8)$ & $55(14.2)$ & \\
\hline Missing data ${ }^{+}$ & $6(0.8)$ & $3(0.8)$ & $3(0.8)$ & \\
\hline \multicolumn{5}{|l|}{ Snack quantity } \\
\hline Moderate/little & 560 (72.9) & $300(80.6)$ & $260(67.4)$ & $<0.001$ \\
\hline Massive & 191 (24.9) & $72(19.4)$ & $119(30.8)$ & \\
\hline Missing data ${ }^{\dagger}$ & $17(2.2)$ & $10(2.6)$ & $7(1.8)$ & \\
\hline
\end{tabular}

*Chi-square test

${ }^{\dagger}$ Missing data because of unanswered questions 
Table 2. Cardio-metabolic risk profiles in total subjects and gender sub-groups

\begin{tabular}{lcccc}
\hline \multirow{2}{*}{ Profile } & $\begin{array}{c}\text { Total subjects, } \\
\text { mean (SD) }\end{array}$ & \multicolumn{2}{c}{$\begin{array}{c}\text { Gender subgroup, } \\
\text { mean (SD) }\end{array}$} & \multirow{2}{*}{$p^{*}$} \\
\cline { 3 - 4 } & $16.0(0.7)$ & $16.2(0.7)$ & $15.8(0.6)$ & $<0.001$ \\
\hline Age (years) & $22.2(4.7)$ & $22.4(5.1)$ & $21.9(4.2)$ & 0.12 \\
\hline BMI $\left(\mathrm{kg} / \mathrm{m}^{2}\right)$ & $55.1(32.5)$ & $54.4(35.0)$ & $55.8(29.8)$ & 0.56 \\
\hline BMI in percentile & $114.2(13.1)$ & $119.3(12.2)$ & $109.2(12.0)$ & $<0.001$ \\
\hline SBP $(\mathrm{mmHg})$ & $72.7(8.9)$ & $73.5(9.3)$ & $71.9(8.5)$ & $\mathbf{0 . 0 2}$ \\
\hline DBP $(\mathrm{mmHg})$ & $86.8(14.1)$ & $83.9(14.3)$ & $89.7(13.3)$ & $<0.001$ \\
\hline Heart rate $(\mathrm{x} / \mathrm{min})$ & $80.8(25.6)$ & $83.7(35.2)$ & $77.9(8.1)$ & $\mathbf{0 . 0 0 3}$ \\
\hline Waist circumference $(\mathrm{cm})$ & $2.6(0.7)$ & $2.8(0.90)$ & $2.5(0.6)$ & $<0.001$ \\
\hline Meals/day & $2.0(1.5)$ & $1.9(1.5)$ & $2.1(1.5)$ & 0.15 \\
\hline Snacks/day & & & &
\end{tabular}

$\mathrm{SD}=$ standard deviation; $\mathrm{BMI}=$ body mass index; $\mathrm{SBP}=$ systolic blood pressure; $\mathrm{DBP}=$ diastolic blood pressure

*Independent $t$-test

Table 3. Categorical cardio-metabolic risk profiles in total subjects and sub-groups

\begin{tabular}{|c|c|c|c|c|}
\hline \multirow{2}{*}{ Categories } & \multirow{2}{*}{ Total, n (\%) } & \multicolumn{2}{|c|}{ Sub-group, n (\%) } & \multirow{2}{*}{$p^{*}$} \\
\hline & & Male & Female & \\
\hline BMI percentile & & & & 0.27 \\
\hline Underweight ( $<5$ th percentile) & $72(9.4)$ & 49 (12.9) & $23(6.0)$ & \\
\hline Normal weight (5th-<85th percentile) & $487(63.5)$ & $213(55.9)$ & $274(71.0)$ & \\
\hline Overweight (85th-<95th percentile) & $121(15.8)$ & $58(15.2)$ & $63(16.3)$ & \\
\hline Obese ( $\geq 95$ th percentile) & $87(11.3)$ & $61(16.0)$ & $26(6.7)$ & \\
\hline SBP percentile & & & & 0.005 \\
\hline Normal SBP (<90th percentile) & $643(84.7)$ & $304(80.9)$ & $339(88.5)$ & \\
\hline Prehypertension (90th-<95th percentile) & $45(5.9)$ & $34(9.0)$ & $11(2.9)$ & \\
\hline Stage I (95th-< stage II threshold) & $60(7.9)$ & $29(7.7)$ & $31(8.1)$ & \\
\hline Stage II hypertension & $11(1.4)$ & $9(2.4)$ & $2(0.5)$ & \\
\hline DBP percentile & & & & 0.69 \\
\hline Normal DBP (<90th percentile) & $604(79.6)$ & $298(79.3)$ & 306 (79.9) & \\
\hline Prehypertension (90th-<95th percentile) & $64(8.4)$ & $28(7.4)$ & $36(9.4)$ & \\
\hline Stage I (95th-< stage II threshold) & $84(11.1)$ & $45(12.0)$ & $39(10.2)$ & \\
\hline Stage II hypertension & $7(0.9)$ & $5(1.3)$ & $2(0.5)$ & \\
\hline SBP with absolute cut-off & & & & $<0.001$ \\
\hline Normal SBP $(<120 \mathrm{mmHg})$ & $490(64.4)$ & $195(51.7)$ & $295(76.8)$ & \\
\hline Elevated SBP $(120-<130 \mathrm{mmHg})$ & $167(21.9)$ & $114(30.2)$ & $53(13.8)$ & \\
\hline Stage I hypertension $(130-<140 \mathrm{mmHg})$ & $84(11.0)$ & $50(13.3)$ & $34(8.9)$ & \\
\hline Stage II hypertension ( $\geq 140 \mathrm{mmHg}$ ) & $20(2.6)$ & $18(4.8)$ & $2(0.5)$ & \\
\hline DBP with absolute cut-off & & & & 0.20 \\
\hline Normal DBP (<80 mmHg) & $599(78.7)$ & $290(76.9)$ & $309(80.5)$ & \\
\hline Stage I hypertension $(80-<90 \mathrm{mmHg})$ & $133(17.5)$ & $69(18.3)$ & $64(16.7)$ & \\
\hline Stage II hypertension ( $\geq 90 \mathrm{mmHg}$ ) & $29(3.8)$ & $18(4.8)$ & $11(2.9)$ & \\
\hline
\end{tabular}

$\mathrm{BMI}=$ body mass index; $\mathrm{SBP}=$ systolic blood pressure; $\mathrm{DBP}=$ diastolic blood pressure

*Gamma-test 
The participants had normal mean cardio-metabolic risk of $\mathrm{BMI}, \mathrm{BP}$, heart rate, and waist circumference between gender. Male teenagers had older age, higher SBP, higher DBP, slower heart rate, and higher meal frequency than female teenagers. BMI percentile was not different between male and female (Table 2 ).

Table 3 showed the parameter of cardio-metabolic risk profiles in total subject and sub-groups gender. The cardio-metabolic risk profiles namely BMI and blood pressure were the same between gender except SBP (Table 3). Fruit intake and snack frequency were not affected the cardio-metabolic risk. Corresponding to gender difference in the four variables of eating behavior, age, and exercise duration, the $p$-value in the eating behavior was analyzed with adjusted $p$ linear regression with gender, duration of exercise, and age factors. After the adjustment, breakfast and vegetable intake affects BMI, whereas Western meal and snack quantity affects heart rate. Although the lower meal frequency had a higher BMI, the analysis can be biased due to imbalanced sample size in each subgroup, with only $5.8 \%$ of subjects having meals $>3$ times daily.

In the gender subgroup analysis (Figure 1), male teenagers with routine vegetable intake had low heart rate $(p=0.03)$. Female teenagers with moderate quantity of snacks had wider waist circumference $(p=0.03)$, those who had Western meals had worse heart rate $(p=0.046)$ and waist circumference $(p=0.001)$, and those with routine breakfast had better BMI $(p<0.001)$, waist circumference $(p=0.02)$, and $\operatorname{DBP}(p=0.004)$. In the overall and subgroup subject analyses, fruit intake and snack frequency did not affect the cardio-metabolic risk parameters $(p>0.05)$ (Figure 1).

\section{DISCUSSION}

This study was aimed to evaluate the association of eating behavior on cardio-metabolic risk factors in high school teenagers. The evaluation was conducted in 768 total subjects. The further evaluation was done in gender groups to considering that gender affects CVD. ${ }^{7}$ In this study, the percentage of male and female subjects that living with parents almost the same. Living with parents may influence the eating behavior of teenagers. A study in China, mothers with elementary or below education level were $49 \%$ (odds ratio and $[95 \%$ confidence interval] $=1.49$ [1.10-2.03]) more likely to serve Western meal to their children than those with college or above education level. ${ }^{21}$ In another study, feeding intervention of parents with their young children improved the dietary quality. ${ }^{22}$ Therefore, in this study, living with parents had similar contribution on both gender group. The subjects had relatively good eating behavior and cardio-metabolic profiles. Regarding the findings that parents positively influenced children's diet so it could be concluded that living with parents was likely to contribute to eating behavior and cardio-metabolic parameters.

In this study, teen subjects had averages of 2.6 times of meals and 2.0 times of snacks. This finding is similar to common daily meal frequency of adult in USA that is, three meals and some snacks between meals. ${ }^{23}$ Eating food, both meals and snacks, supplies nutrients required for daily living. In contrast, another finding showed that the subjects did not consume excessive nutrition, as shown in the following lines of evidence: higher proportion of subjects with moderate quantity of meals and snack, routine vegetable intake, and avoidance of Western/highcalorie meals. ${ }^{15}$ In this study, vegetable and fruit daily intake represented a meal with high contents of fiber and nutrients, which are favorable for cardiovascular health; meanwhile, Western/high-calorie meals are detrimental for cardiovascular health. ${ }^{24,25}$ The overall subjects had lived with good eating behavior with more proportion of teenagers with healthy eating behavior. A low proportion of teenagers had Western meals. This finding contradicts that in reference, which showed the high prevalence of fast food consumption in major cities in China among children. ${ }^{21}$ In the present study, the frequencies of eating breakfast, vegetables, fruits, and Western meals were not different between the gender groups. The consumption of vegetables and moderate snack was higher in the male group than in the female group. Our finding showed different result from previous study which conducted a survey among 12-18 year old Australian teenagers, where male teenagers consumed more high-calorie fat and sugar. ${ }^{26}$ Most subjects lived with their parents, and their meals prepared at home were likely to cause no disparity in most eating behavior between the gender groups.

Subjects with exercise activity $\geq 120 \mathrm{~min}$ weekly with a lower proportion was female teenagers (17.9\%). However, a reduction in exercise activity is associated with the decline in energy expenditure. The increase in obesity epidemic is occurring against the background of continuous decline in the energy expenditure. ${ }^{15}$

mji.ui.ac.id 

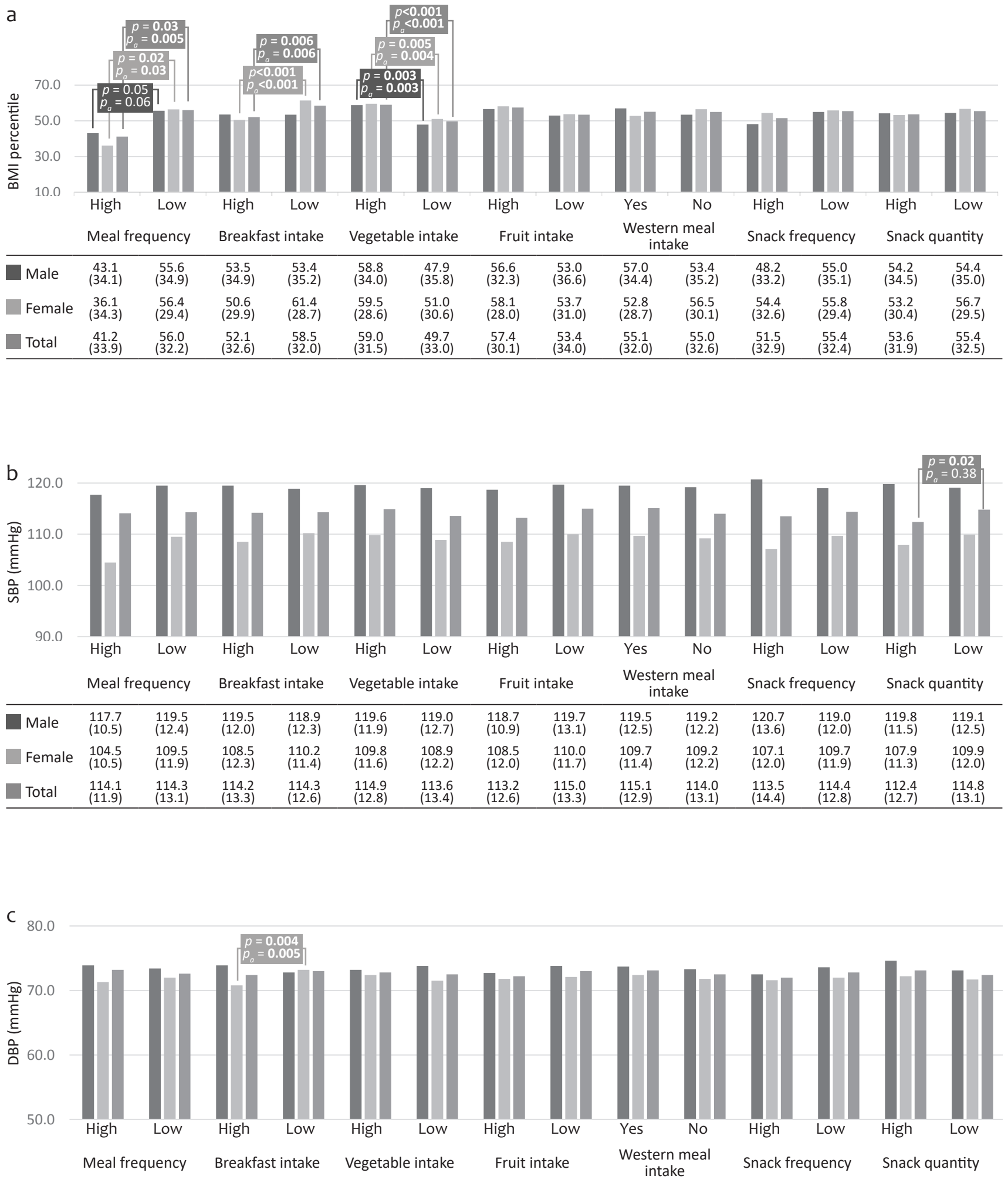

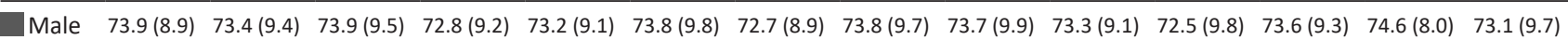

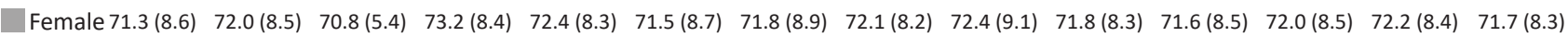

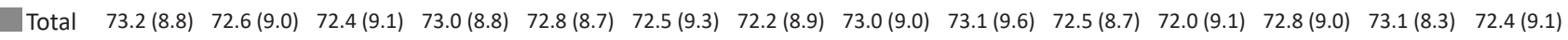

Figure 1. Association of eating behaviors and cardio-metabolic risk profiles. BMI=body mass index; $\mathrm{SBP}=$ systolic blood pressure; $\mathrm{DBP}=$ diastolic blood pressure; $p_{a}=$ adjusted $p$-value to gender, exercise, and age. All data were describe as mean (SD). Other variables that were not mentioned above had $p>0.05$ $p$-value analyzed with independent $t$-test 

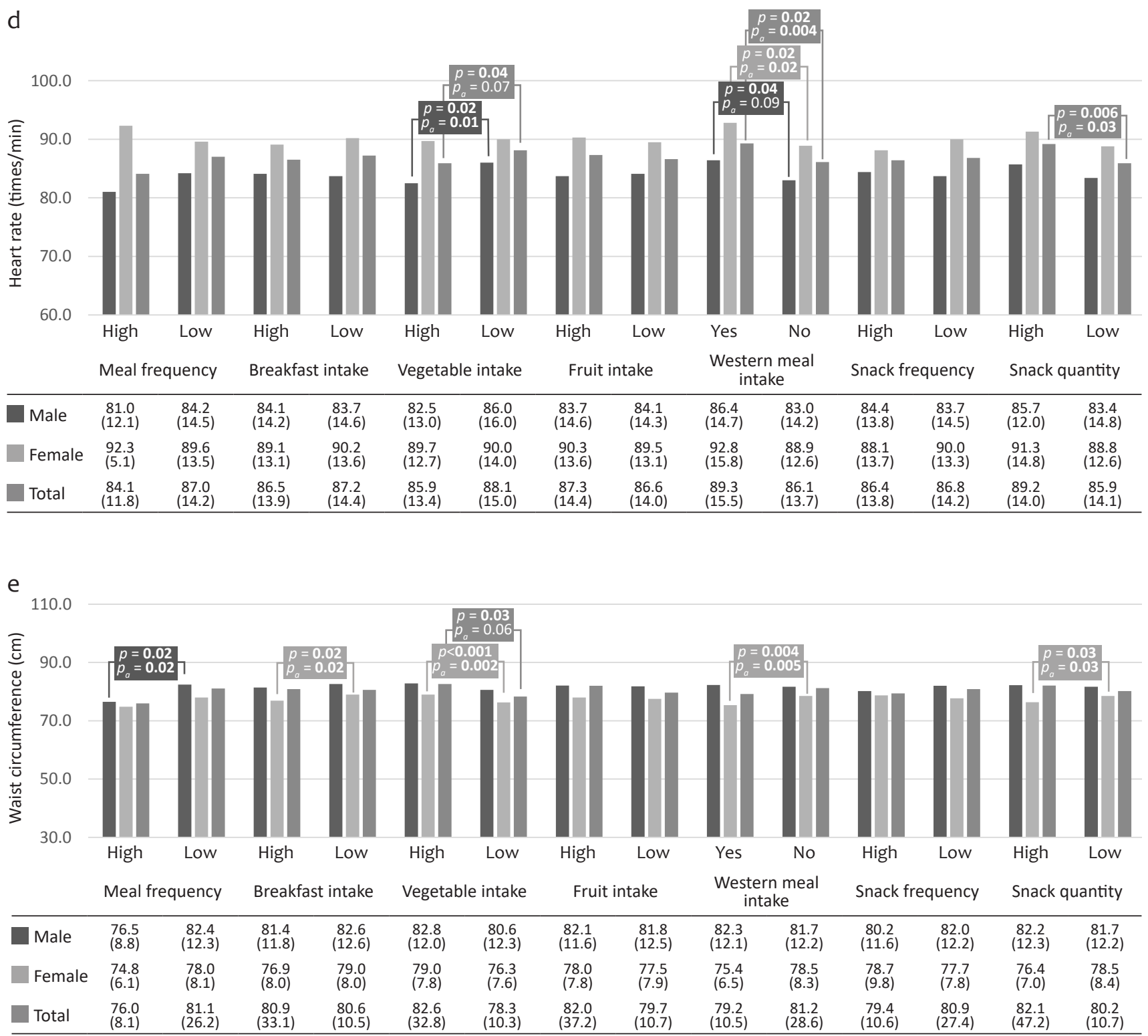

Figure 1. (continued)

Therefore, exercise is the most urgent required factor for CVD prevention. The low exercise rate among subjects will cause a definite CVD problem in their future life. ${ }^{27}$

The prevalence of high BP among teenagers 15-17 years old was $13.6 \%$ for SBP in percentile and $21.3 \%$ for DBP in percentile; these values exceed that (5.3\%) obtained in National Basic Health Survey in 2013. ${ }^{16}$ Moreover, the exact hypertension rates in the community were generally higher than the reported prevalence because the disease progresses without symptoms and is often under-recognized. ${ }^{6}$ This finding can be considered as early signal of hypertension and should be anticipated for prevention of CVD in their future life. Healthy lifestyle, including healthy eating habits, and maintenance of cardio-metabolic risk are an important solution. The prevalence of hypertension was higher in male teenagers than female at $18.1 \%$ versus $9.4 \%$ for SBP $(p<0.001)$ and $23.1 \%$ versus $18.7 \%$ $(p=0.20)$ for DBP. This finding conforms to the global data that male subjects have higher prevalence of hypertension than female subjects before the menopausal period. ${ }^{7}$

$\mathrm{BMI}$ in percentile for male teenagers were similar with female $(p=0.56)$, while the waist circumference of male wider than female $(p=0.003)$. However, the difference between female and male teen around 6 $\mathrm{cm}$. According to the standard, the difference of waist circumference should be at $10 \mathrm{~cm} .{ }^{8}$ Measuring obesity using BMI is practical, fast, easy, and inexpensive, 
but the method cannot distinguish body mass with and without fat; 19 meanwhile, waist circumference can represent the subject's central obesity and fat mass. The overall subjects had normal BMI and waist circumference. Another finding showed that gender disparity in obesity was not persistent. Evidence from a national survey revealed that more female subjects had central obesity ${ }^{28}$ and similar prevalence in worldwide, particularly in lower middle income countries, showed that more obesity in female subjects. ${ }^{9}$ The intraabdominal fat was lower in girls, as reported by a population-based study on 12-18 year old teenagers. ${ }^{29}$ Female teenagers had more overweight/obese subjects with wider waist circumference but less overweight/ obese subjects with BMI (Table 2). ${ }^{19}$

The male subjects had worse SBP but not DBP than female subjects; similar results were found in SBP/DBP in percentile and absolute measurement. This finding conforms to the 2017 ACC/AHA hypertension guideline that BP in children can be measured in percentile; for teenagers aged $\geq 14$ years, BP is classified based on the JNC7 threshold for adults (Table 2 and 3). ${ }^{7}$

In overall subjects, teenagers with more frequent breakfast daily had low BMI (adjusted $p=0.007$ ). Routine breakfast would avoid skipping meal, which induced snack consumption. ${ }^{30}$ Snack consumption from dessert or sweets were likely related to highcalorie intake and BMI increase. ${ }^{31}$ In this study, low intake of vegetable but not fruit was associated with BMI, waist circumference, SBP, and DBP. Other study conducted in teenagers aged $\geq 16$ years showed that fruit, salad, cereals, and fish intake had lower DBP ( $p=0.0025)$ after adjustment for age, gender, and physical activity. ${ }^{26}$

This study described that eating behavior, meal frequency, breakfast, vegetable intake, fruit intake, western/high-calorie meal, snack frequency, and snack quantity, did not affect BP and waist circumference in overall subjects but affected waist circumference in the female group. The physiological systems in teenagers are likely to compensate for the effect, since no unfavorable clinical effect due to unhealthy lifestyle had emerged yet. Age $>40$ year old had an impact in the development and incidence of CVDs. ${ }^{32,33}$ However, eating behavior as one of factors may contribute partially to cardio-metabolic risk. Other factors, such as interests and activities, family history of CVD, and socioeconomic background, also contributed to CVD risk. ${ }^{2}$ As family history of CVD is a cardiovascular risk factor, ${ }^{3}$ in this study most subjects could not provide those information.

Similar to the finding in the overall subjects, eating behavior were not associated with the subject's SBP/ DBP in both gender groups, except for routine breakfast in female teenagers that had positive significant effect on DBP. Skipping breakfast would increase CVD risk and it was higher in female participants. ${ }^{34}$ Adjusted $p$ results from the association of eating behavior and cardiometabolic risk which adjusted duration of exercise and age factors after being classified by gender. A study conducted in Tokyo showed that DBP is a more important BP component for prediction of developing hypertension than SBP in <50-year-old subjects. Reducing DBP can prevent hypertension. The study recommended initiating early therapeutic lifestyle changes among younger subject aged $<50$ years when slight increase in DBP occurs. ${ }^{35}$ Routine breakfast could likely decrease hunger and snack craving throughout the day and maintain bodyweight accordingly. The observation from this study supported the effect of routine breakfast on better cardio-metabolic outcomes, including better BMI in percentile in the overall subjects. The positive effect of breakfast was more intense in female teenagers, as evident by better $\mathrm{BMI}$ in percentile, DBP, and waist circumference.

The mean values of cardio-metabolic risk parameters in the overall subjects were normal (Table 2); nevertheless, some subjects had a risk of potential CVD (Table 3). This finding should be the reason for concern by parents, teachers, clinicians, and health educators/ authorities. Implementation of healthy lifestyle as early as possible will be beneficial to control CVD morbidity and mortality rate in future life. ${ }^{36}$ In a prospective followup study in hypertensive subjects, the intervention was beneficial regardless of the change in body weight, resulting in achieving lower BP and low-density lipoprotein level. ${ }^{37}$ Similarly, one study conducted in a community in 2018 confirmed that health education by pharmacists increased the proportion of non-smoking subjects and reduced the CVD risk. ${ }^{38}$

We found some abnormality results in this study, for example, teenagers with routine vegetable intake had higher BMI, and female teenagers with routine vegetable intake had wider waist circumference than their peers $(p<0.001$ versus 0.10 , respectively). The unusual results occurred due to the limitation of the study. The study was conducted with a cross-sectional design and could not reveal the subject's baseline 
condition. The number of subjects varied in each school and/or province and in each subgroup. Moreover, cardio-metabolic risk parameters were accumulated by multiple factors. Our study observed eating behavior on seven variables/factors. We declared that one single factor of eating behavior was insufficiency to show good relationship with cardiometabolic factors. Further studies with randomized control method or good design cohort should be conducted to evaluate correlation among variables (Figure 1).

The other cardio-metabolic risk factors, such as levels of cholesterol, triglyceride, and blood glucose, were not measured due to the limitations of the study method. We recommend that further studies should be conducted with cohort design to confirm the present results and determine all other causes of cardiometabolic risk among teenagers. In conclusion, eating behaviors, including routine breakfast, low quantity of snack intake, and avoiding Western/high-calorie meals were likely to have positive effect on cardio-metabolic risk factors. Further studies are suggested to generalize the results to other populations.

\section{Conflict of Interest}

The authors affirm no conflict of interest in this study.

\section{Acknowledgment}

The authors would like to thank the head of schools for the research permit and to all students for their participation in this study. The authors also thank the Lembaga Penelitian dan Pengabdian Kepada Masyarakat Universitas Sanata Dharma for the research funding support.

\section{Funding Sources}

This study was financed by a grant from LPPM USD (annual budget year 2018).

\section{REFERENCES}

1. Pariona A. Leading causes of death in Indonesia [Internet]. World Atlas. 2017 [cited 2018 Sep 25]. Available from: https:// www.worldatlas.com/articles/leading-causes-of-death-inindonesia.html.

2. Suhadi R, Linawati $Y$, Wulandari $E T$, Viriginia $D M$, Setiawan $\mathrm{CH}$. The metabolic disorders and cardiovascular risk among lower socioeconomic subjects in Yogyakarta-Indonesia. Asian J Pharm Clin Res. 2017;10(3):367-72.

3. Hong YM. Atherosclerotic cardiovascular disease beginning in childhood. Korean Circ J. 2010;40(1):1-9.

4. Charakida M, Jones A, Falaschetti E, Khan T, Finer N, Sattar N, et al. Childhood obesity and vascular phenotypes: a population study. J Am Coll Cardiol. 2012;60(25):2643-50.

5. Riley $M$, Bluhm B. High blood pressure in children and adolescents. Am Acad Fam physician. 2012;85(7):693-700.

6. Anyaegbu El, Dharnidharka VR. Hypertension in the teenager. Pediatr Clin North Am. 2014;61(1):131-51.

7. Whelton PK, Carey RM, Aronow WS, Ovbiagele B, Casey DE, Smith SC, et al. 2017. ACC/AHA/AAPA/ABC/ACPM/AGS/APhA/ ASH/ASPC/NMA/PCNA guideline for the prevention, detection, evaluation, and management of high blood pressure in adults: executive summary: a report of the American College of Cardiology/American Heart Association Task Force on Clinical Practice Guidelines. J Am Coll Cardiol. 2018:71(19);2199-269.

8. World Health Organization. Waist circumference and waisthip ratio report of a WHO expert consultation. Geneva: World Health Organization; 2008 [cited 2018 Oct 24]. p. 1-34. Available from: https://apps.who.int/iris/bitstream/ handle/10665/44583/9789241501491 eng.pdf;jsessionid=D2314 69B3272A7BA0697C8C12E0109B4? sequence=1.

9. Kanter R, Caballero B. Global gender disparities in obesity: a review. Adv Nutr An Int Rev J. 2012;3(4):491-8.

10. Centers for Disease Control and Prevention. Healthy weight. Child \& teen BMI calculator [Internet]. 2018 [cited 2018 Oct 24]. Available from: https://www.cdc.gov/healthyweight/bmi/ calculator.html.

11. EBMcalc System. Blood pressure percentile for boys (2-17 years) [Internet]. 2018 [cited 2018 Oct 24]. Available from: https://www.merckmanuals.com/medical-calculators/ BloodPressurePercentBoys.htm.

12. EBMcalc System. Blood pressure percentile for girls (2-17 years) [Internet]. 2018 [cited 2018 Oct 24]. Available from: https://www.merckmanuals.com/medical-calculators/ BloodPressurePercentGirls.htm.

13. Sahoo K, Sahoo B, Choudhury AK, Sofi NY, Kumar R, Bhadoria AS. Childhood obesity: causes and consequences. J Fam Med Prim care. 2015;4(2):187-92.

14. Popkin BM, Adair LS, Ng SW. Global nutrition transition and the pandemic of obesity in developing countries. Nutr Rev. 2012;70(1):3-21.

15. Wiklund $P$. The role of physical activity and exercise in obesity and weight management: time for critical appraisal. J Sport Heal Sci. 2016;5(2):151-4.

16. BPDANPKesehatan. Riset kesehatan dasar 2013 [Internet]. 2013 [cited 2018 Oct 24]. Available from: www.depkes.go.id/ resources/download/general/Hasil Riskesdas 2013.pdf\%OA\%0A.

17. Dupont WD, Plummer WDJ. PS: power and sample size calculation [Internet]. 2018 [cited 2018 Oct 24]. Department Biostatistics Vanderbilt University. Available from: http:// biostat.mc.vanderbilt.edu/wiki/Main/PowerSampleSize.

18. Davis BH, McLaren CE, Carcio AJ, Wong L, Hedley BD, Keeney M, et al. Determination of optimal replicate number for validation of imprecision using fluorescence cell-based assays: proposed practical method. Cytometry B Clin Cytom. 2013;84(5):329-37.

19. Ayer J, Charakida M, Deanfield JE, Celermajer DS. Lifetime risk: childhood obesity and cardiovascular risk. Eur Heart J. 2015;36(22):1371-6.

20. Paolo P. Need for a revision of the normal limits of resting heart rate. Hypertension. 1999;33(2):622-5.

21. Zhao $\mathrm{Y}$, Wang $\mathrm{L}$, Xue $\mathrm{H}$, Wang $\mathrm{H}$, Wang $\mathrm{Y}$. Fast food consumption and its associations with obesity and hypertension among children: results from the baseline data of the Childhood Obesity Study in China Mega-cities. BMC Public Health. 2017;17(1):933.

22. Arlinghaus KR, Vollrath $K$, Hernandez DC, Momin SR, O'Connor TM, Power TG, et al. Authoritative parent feeding style is associated with better child dietary quality at dinner among low-income minority families. Am J Clin Nutr. 2018;108:1-7.

23. Mattson MP, Allison DB, Fontana L, Harvie M, Longo VD, Malaisse WJ. Meal frequency and timing in health and disease. In: Proceeding of the National Academy of Sciences of the United States of America. 2014. p. 16647-53.

24. Slavin JL, Lloyd B. Health benefits of fruits and vegetables. Adv Nutr. 2012;3(4):506-16.

25. Anand SS, Hawkes C, de Souza RJ, Mente A, Dehghan M, Nugent $\mathrm{R}$, et al. Food consumption and its impact on cardiovascular disease: importance of solutions focused on the globalized food system: a report from the workshop convened by the World Heart Federation. J Am Coll Cardiol. 2015;66(14):1590-614.

26. McNaughton SA, Ball K, Mishra GD, Crawford DA. Dietary 
patterns of adolescents and risk of obesity and hypertension. $J$ Nutr. 2008;138(2):364-70.

27. Tian D, Meng J. Exercise for prevention and relief of cardiovascular disease: prognosis, mechanisms, and approaches. Oxid Med Cell Longev. 219;2019:3756750.

28. Harbuwono DS, Pramono LA, Yunir E, Subekti I. Obesity and central obesity in Indonesia: evidence from a national health survey. 2018;27(2):114-20.

29. Syme C, Abrahamowicz M, Leonard GT, Perron M, Richer $\mathrm{L}$, Veillette $\mathrm{S}$, et al. Sex differences in blood pressure and its relationship to body composition and metabolism in adolescence. Arch Pediatr Adolesc Med. 2009;163(9):818-25.

30. Yusuf S, Rangarajan S, Teo K, Islam S, Li W, Liu L, et al. Cardiovascular risk and events in 17 low-, middle-, and highincome countries. N Engl J Med. 2014;371(9):818-27.

31. Barnes TL, French SA, Harnack LJ, Mitchell NR, Wolfson J. Snacking behaviors, diet quality, and body mass index in a community sample of working adults. J Acad Nutr Diet. 2015;115(7):1117-23.

32. Hajar R. Risk factors for coronary artery disease: historical perspectives. Heart Views. 2017;18(3):109-14.

33. Rodgers JL, Jones J, Bolleddu SI, Vanthenapalli S, Rodgers LE,
Shah K, et al. Cardiovascular risks associated with gender and aging. J Cardiovasc Dev Dis. 2019;6(2):19.

34. Lee HJ, Jang J, Lee SA, Choi DW, Park EC. Association between breakfast frequency and atherosclerotic cardiovascular disease risk: a cross-sectional study of KNHANES data, 2014-2016. Int J Environ Res Public Health. 2019;16(10):1853.

35. Kanegae H, Oikawa T, Okawara Y, Hoshide S, Kario K. Which blood pressure measurement, systolic or diastolic, better predicts future hypertension in normotensive young adults? J Clin Hypertens. 2017;19(6):603-10.

36. Cote AT, Harris KC, Panagiotopoulos C, Sandor GCS, Devlin AM. Childhood obesity and cardiovascular dysfunction. J Am Coll Cardiol. 2013;62(15):1309-19.

37. Pascual JM, Rodilla E, Costa JA, Perez-Lahiguera F, Gonzalez C, Lurbe $\mathrm{E}$, et al. Body weight variation and control of cardiovascular risk factors in essential hypertension. Blood Press. 2009;18(5):247-54.

38. Suhadi R, Virginia DM, Setiawan $\mathrm{CH}$. The effect of health education by pharmacists on 10-year atherosclerotic cardiovascular disease risk: a cluster-randomized control study in a low socioeconomic status Javanese population. J Prim Care Community Health. 2018;9:2150132718773674. 